\title{
PERFIL DE CONCERNS E PROJETO DE SISTEMAS PRODUTOS-SERVIÇOS NA GASTRONOMIA: UMA DISCUSSÃO METODOLÓGICA
}

\author{
Clarissa Brinckmann Oliveira Hirano \\ Universidade do Vale do Rio dos Sinos \\ clarissabo@unisinos.br \\ Filipe Campelo Xavier da Costa \\ Universidade do Vale do Rio dos Sinos \\ fcampelo@unisinos.br
}

Resumo: $O$ presente artigo tem como objetivo discutir de que forma a análise dos concerns (disposições, padrões que as pessoas trazem para o processo emocional sobre um determinado estímulo) dos usuários de uma operação gastronômica pode contribuir para o desenvolvimento de um sistema produto serviço. Para tanto, a Teoria dos Appraisals, modelo teórico baseado em uma relação de causalidade entre uma emoção e um elemento projetável, é abordada como a perspectiva teórica para o desenvolvimento desse estudo. Através de uma pesquisa exploratória, o artigo propõe uma discussão acerca da aplicabilidade do concern profile (que é uma forma de organizar a análise e a compreensão dos concerns dos usuários sobre determinado estímulo) no processo de projeto de um bistrô. Para tanto, a investigação foi conduzida através de duas etapas de coleta de dados: entrevistas em profundidade com usuários de bistrôs com o objetivo de confeccionar um concern profile; e a segunda etapa da coleta, foi a propositura de um grupo focal para discutir o potencial do concern profile para o desenvolvimento de projetos de operações gastronômicas. O estudo permite sugerir que é possível tratar o concern profile como um relevante insumo para a promoção de diretrizes projetuais.

Palavras-chave: experiência do usuário, sistema produto-serviço, teoria dos appraisals, análise de concerns.

\footnotetext{
Abstract: This article aims to discuss how the concern analysis (beliefs, motivations that people bring to the emotional process on a particular stimulus) of bistro users can contribute for a better product-service system development Therefore, the Appraisal Theory, theoretical model based on a causal relationship between an emotion and a designed element is addressed as a perspective for the development of this study. Through an exploratory research, the article proposes a discussion on the concern profile usage (which is a way to organize the analysis and understanding of the users' concerns on a particular stimulus) in a bistro design process. For this reason, the investigation was conducted through two data collection
} 
stages: in-depth interviews with bistro users in order to build a concern profile; and the second stage, a focus group was conducted to discuss the potential of concern profile for the fod operation development projects. The study allows us to suggest that it is possible to consider the concern profile as meaningful input for design guidelines development.

Keywords: user experience, product-service system, appraisal theory, concern analysis.

\section{INTRODUÇÃO}

A atividade projetual vem ganhando sofisticação e abrangência ao tratar em seus processos temáticas e perspectivas teóricas até então distantes do seu domínio. Compreender a natureza da experiência do usuário e seus componentes como insumo para o desenvolvimento de projetos de produtos ou serviços com maior probabilidade de sucesso tem sido explorado por áreas como design para experiência e design emocional. Esse é o ponto de partida o propósito desse estudo, que busca discutir de que forma o design pode contribuir com projetos focados em proporcionar uma experiência emocional positiva nos usuários de um determinado serviço gastronômico. de bistrôs.

O design emocional é a área que busca projetar para que determinadas emoções sejam despertadas ou evitadas através do uso dos artefatos ou serviços (DEMIR et al., 2009). É uma prática que utiliza a pesquisa direta com usuários e tem a função de nutrir um projeto com informações que possam potencializar os efeitos emocionais pretendidos. Dentre as abordagens que compõe esse campo, destaca-se a teoria que foi utilizada neste estudo que é a abordagem trazida da Psicologia Cognitiva para o design. Chama-se Teoria dos Appraisals e foi trazida para o design por Desmet (2002). Esse modelo propõe a compreensão da relação emocional das pessoas com os objetos e é baseado em uma relação de causalidade entre um elemento projetável e uma emoção.

Neste modelo é sugerido que três variáveis fazem parte do processo de desencadeamento das emoções: o interesse ou demandas das pessoas (concerns), o estímulo (produto ou serviço) e a avaliação (appraisal). O concern é o termo utilizado para descrever interesses, objetivos, demandas e até mesmo padrões em relação aos que se espera de um produto. Nesta teoria, concerns de diferentes usuários podem provocar emoções também distintas, já que a resposta emocional é individual e objeto de uma avaliação que o usuário em particular faz sobre o produto (TONETTO, 2012). Segundo Demir, Ozkaramanli e Desmet, (2010), os usuários podem ter três tipos de concerns. São eles, concerns em relação ao produto, em relação às atividades desenvolvidas com o produto e concerns relativos às relações do produto com a vida da pessoa. Assim, de alguma forma, os concerns moldam as avaliações (appraisals) dos usuários.

A partir da base teórica da Teoria dos Appraisals, pretende-se compreender os concerns dos usuários de bistrô para então construir um concern profile que possa ser utilizado como fomento em projetos de design estratégico. Neste viés, é sabido que 
muitos designers optam, como alternativa para projetar (DEMIR; DESMET; OZKARAMANLI, 2010), por elaborar uma síntese de conteúdos sobre a experiência do usuário sob a forma de um concern profile, ou perfil de concerns do usuário. Este perfil tem a funcionalidade de organizar os concerns dos usuários de maneira que facilite a compreensão e possa ser introjetado nos projetos de design. A utilização de um concern profile pode tornar mais tangível as intenções de projetos quando o foco é trabalhar com experiência do usuário e suas percepções emocionais.

Dessa maneira, o estudo possui como temática central a relação entre o uso de bistrôs e a experiência emocional evocada por esta vivência. Para tanto, a investigação delimita-se na análise das demandas dos usuários de bistrô para então fornecer dados para a discussão de um projeto de um sistema produto-serviço. Para os fins deste estudo, um sistema produto serviço de um bistrô representa uma oferta integrada de soluções que proponha uma sinergia entre as dimensões de produto, serviço e comunicação. Neste viés, produto é toda comida ofertada no bistrô, as louças em geral, a decoração do ambiente e layout das mesas. Serviço contempla o atendimento em toda sua amplitude, ou seja, a forma de atender, de receber, de servir à mesa. Comunicação de um bistrô representa a fachada do estabelecimento, ponto comercial e toda forma de comunicação com os usuários. Assim, este artigo tem como objetivo compreender como o designer pode se utilizar da análise de concerns dos usuários de bistrô para o desenvolvimento de um sistema produto serviço. O artigo visa, ainda, como desdobramentos específicos, compreender os concerns dos usuários de bistrôs e avaliar a contribuição destes como insumo no processo de projeto.

Acredita-se que este estudo colabora para um melhor entendimento acerca do mercado da Gastronomia. A demanda por novas experiências de consumo no contexto alimentar, nos dias atuais, extrapola as características pragmáticas e funcionais de representarem apenas uma refeição. Há uma procura por parte dos consumidores, de alimentarem-se melhor e, ainda, de maneiras diferentes. Alimentar-se unicamente para o suprimento de necessidades fisiológicas não corresponde mais a realidade atual (DÓRIA, 2009). Embora o alimento seja um elemento importante à discussão do tema, os esforços deste estudo serão direcionados à discussão do design como articulador de processos criativos em prol de experiências gastronômicas que sejam mais interessantes.

A proposta de interlocução entre o design de sistemas produto-serviço, design para experiência, design para emoção e a Gastronomia se faz importante já que estas áreas se encontram em um momento de transição. No design, as premissas de projeto como forma e função, na atualidade, não correspondem mais às soluções esperadas pelos consumidores. Há uma necessidade de desenvolvimento de contextos que evoquem experiências positivas e de bases e valores significativos para os usuários. Portanto, um dos possíveis caminhos a serem percorridos para alcançar resultados inovadores seja ampliando o foco das pesquisas em compreender as reações emocionais das pessoas quando interagindo com produtos e serviços.

A abordagem metodológica deste artigo é baseada em estudo exploratório com informações qualitativas. A proposta foi dividir o método em duas etapas. A primeira etapa consistiu na elaboração e aplicação de entrevistas em profundidade com usuários de bistrôs. Esta fase teve como objetivo compreender os concerns dos usuários e construir um material (concern profile) para fomentar a segunda etapa da coleta de dados. A segunda etapa foi a realização de um grupo focal com especialistas 
que possuem experiência em projetos de operações gastronômicas. O objetivo da discussão do grupo focal foi avaliar, na visão dos especialistas, a utilidade do concern profile como insumo para um projeto de bistrô à luz do design estratégico. O material coletado nas duas fases de coleta foi analisado com base na técnica de Análise de Conteúdo (MORAES, 1999).

\section{PROCEDIMENTOS METODOLÓGICOS}

O estudo teve origem com a definição do problema de pesquisa que foi estabelecido considerando os interesses da área e a relevância do tema. A definição do método baseado na abordagem dos appraisals partiu do estudo de Desmet (2002) e Desmet et al. (2010) no qual é sugerido a divisão de quatro etapas para projetos de design e emoção. Estas etapas envolvem a especificação de um tema, a identificação dos concerns de um determinado grupo de pessoas, o desenvolvimento de um perfil de concerns e, por fim, o projeto do produto . Como este estudo não tem o objetivo de desenvolver um projeto específico, optou-se pela exclusão da última etapa.

A análise e investigação de concerns são usualmente vinculadas a técnicas e métodos de pesquisa exploratórios ou de observação (OSKARAMANLI; DESMET, 2012; TONETTO, 2012). Nesta pesquisa, buscou-se, através de duas etapas exploratórias, com a condução de entrevistas em profundidade e o desenvolvimento de um grupo focal, a obtenção de informações sobre os concerns dos usuários de bistrô e sua aplicabilidade em um projeto de design estratégico respectivamente.

Esta pesquisa foi desenvolvida em duas etapas. A figura 1 apresenta o fluxograma do desenvolvimento da pesquisa e nas seções seguintes o detalhamento de cada etapa.

Figura 1 - Fluxograma da pesquisa

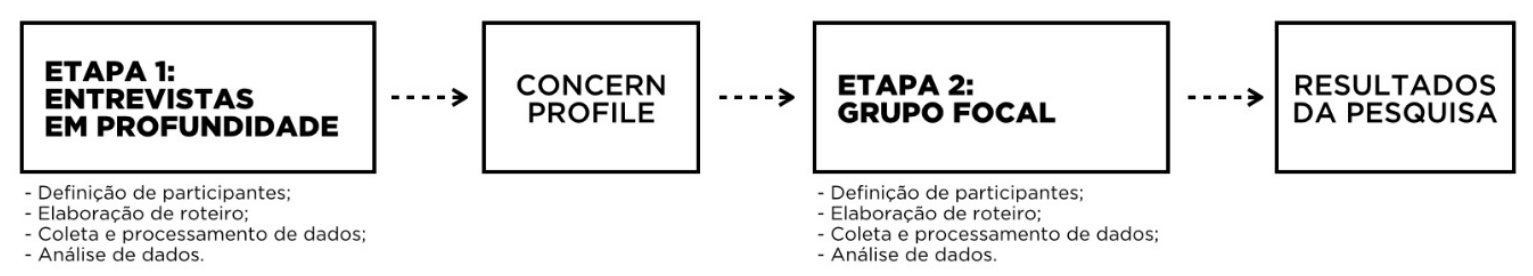

Fonte: Elaborado pelos autores

\subsection{Entrevistas em Profundidade com Usuários de Bistrô}

Na primeira etapa, optou-se pela condução de entrevistas em profundidade com roteiros semiestruturados como método de obtenção de dados qualitativos a respeito dos concerns dos usuários de bistrô (frequência mínima de duas vezes ao mês). Foram entrevistadas sete pessoas com idade entre 25 e 60 anos com formação profissional diversa, sendo as entrevistas gravadas e transcritas na íntegra para realização de análise de conteúdo. O número de entrevistados foi delimitado por saturação (FONTANELLA; RICAS; TURATO, 2008).

$O$ roteiro de entrevista semi-estruturado seguiu as recomendações de Oskaramanli e Desmet (2012) e Tonetto (2012) em trabalhos de investigações de cunho emocional, através da utilização da técnica de laddering. Este recurso é 
apresentado por Reynolds e Gutman (1988) como uma técnica de intervenção sistemática em que o entrevistador passa a questionar cada uma das respostas dadas pelo participante, visando ampliar o raciocínio do entrevistado e fazer associações mais ricas sobre atributos significativos. O desenvolvimento do roteiro foi construído buscando abordar a investigação dos concerns baseados em variáveis referentes à relação dos usuários e bistrôs, considerando as dimensões atendimento, menu, ambientação e comunicação. Foi necessário delimitar algumas características para exemplificar e tematizar os bistrôs investigados aos entrevistados, que deveriam ter as seguintes características: local pequeno (capacidade de até 40 pessoas), com menu variável conforme a sazonalidade e/ou deliberação do chef e que oferece um prato do dia.

O tratamento dos dados seguiu a técnica de Análise de Conteúdo. Nesta pesquisa, a categorização foi feita com base no universo empírico a partir das verbalizações extraídas das entrevistas, permitindo a identificação dos concerns mais recorrentes e significativos e gerando agrupamentos para a estruturação do perfil de concerns.

\subsection{Grupo Focal com Experts}

Após a condução das entrevistas em profundidade, a realização de um grupo focal teve por objetivo discutir a introdução do concern profile no processo de projeto de um bistrô. Dadas as características e intenções desta fase, optou-se pela realização do grupo focal para que os especialistas fossem estimulados a debater sobre experiências de projeto de operações gastronômicas e a aplicabilidade da inclusão de informações dos usuários (concern profile) no desenvolvimento de um projeto de bistrô.

Foram selecionadas seis especialistas, com distintas formações e áreas de especialidade (empresários do setor, publicitário, arquiteto, designer, professor de gastronomia), que tivessem um denominador em comum: experiência em projetos de operações gastronômicas. O roteiro para condução desse grupo focal estava calcado em dois questionamentos: como ocorre o processo de projeto das operações gastronômicas que os especialistas já participaram e qual a avaliação dos especialistas sobre a utilização de um concern profile no projeto de um bistrô.

O grupo focal teve duração aproximada de duas horas e foram feitos registros em áudio e video, sendo posteriormente transcritos e analisados. A condução do grupo foi feito pela primeira autora desse artigo.

Passo seguinte, foi introduzido o recorte da pesquisa e estabelecido que a discussão seria orientada ao desenvolvimento de bistrôs. A pesquisadora convidou os participantes a fazerem um exercício de projeto, momento que foi apresentado o concern profile para o grande grupo. O exercício ocorreu da seguinte maneira: o grupo foi dividido em três duplas. A divisão ocorreu de forma aleatória; para cada dupla foi entregue cartões coloridos com as frases que representam os concerns dos usuários de bistrô (resultado da primeira etapa da coleta de dados) e que deveriam ser discutidos; foi retomada a discussão no grande grupo trazendo como ponto de referência as informações dos cartões. O grupo iniciou a discussão considerando que as frases entregues fossem utilizadas como insumos para o processo de projeto de um bistrô.

As transcrições dos áudios foram analisadas e examinadas a partir de categorias teóricas associadas ao desenvolvimento de sistemas produto-serviço e seus resultados, ou seja, produto, serviço e comunicação. As subcategorias (avaliações detalhadas 
sobre a contribuição do concern profile no projeto de design estratégico de um bistrô) foram definidas com base nos discursos dos especialistas.

\section{APRESENTAÇÃO DOS RESULTADOS}

A organização deste capítulo se dá em duas seções: na primeira seção serão expostas as análises da primeira etapa da pesquisa com a explicação das categorias de análise e a construção do concern profile; na segunda seção serão expostos os dados do grupo focal e as sugestões de desdobramentos projetuais.

\subsection{Análise dos Concerns dos Usuários}

Esta seção segue o modelo de organização, análise e construção do perfil de concerns proposto por Demir, Desmet e Oskaramanli (2010), seguindo a classificação sugerida pelos autores (produto, atividade e vida). Com o objetivo de facilitar a visualização dos concerns por parte dos profissionais que participaram do grupo focal, as categorias empíricas de análise foram elaboradas com expressões adaptadas dos concerns dos usuários entrevistados. No quadro seguinte, apresenta-se o esquema de categorias que constituem o concern profile bem como as frases que correspondem ao concern profile propriamente.

Quadro 1 - As categorias de análise e o concern profile

\begin{tabular}{|c|c|c|c|}
\hline $\begin{array}{l}\text { Categorias de } \\
\text { análise }\end{array}$ & Afirmativas de Concerns & Frase que representa o concern & $\begin{array}{l}\text { Tipologia do } \\
\text { concern } \\
\text { (Desmet, } \\
\text { 2010) }\end{array}$ \\
\hline \multirow{4}{*}{$\begin{array}{l}\text { Qualidade da } \\
\text { comida }\end{array}$} & Apresentação do prato & $\begin{array}{l}\text { A apresentação do prato é a primeira } \\
\text { impressão que se tem da comida. }\end{array}$ & Produto \\
\hline & Comida com sabor & $\begin{array}{l}\text { Comida de bistrô é comida que se sente o } \\
\text { sabor de cada item. O chef não tem } \\
\text { medo de temperar. }\end{array}$ & Produto \\
\hline & $\begin{array}{l}\text { Percepção de que foi } \\
\text { feito por confecção } \\
\text { artesanal }\end{array}$ & $\begin{array}{l}\text { Bistrô tem característica de lugar com } \\
\text { comida hand made" }\end{array}$ & Produto \\
\hline & Comida fresca & $\begin{array}{l}\text { Comida de bistrô tem que ser comida } \\
\text { sazonal, com ingredientes frescos. }\end{array}$ & Produto \\
\hline \multirow{5}{*}{$\begin{array}{l}\text { Ambiente } \\
\text { confortável }\end{array}$} & Detalhes na decoração & $\begin{array}{l}\text { Gosto de bistrô cheio de detalhes pois } \\
\text { eles complementam a decoração e } \\
\text { transmitem conforto. }\end{array}$ & Produto \\
\hline & $\begin{array}{l}\text { Decoração com materiais } \\
\text { que transmitam calor. }\end{array}$ & $\begin{array}{l}\text { Gosto de móveis de madeira, tons } \\
\text { acamurçados, listrados, xadrez. }\end{array}$ & Produto \\
\hline & \multirow{2}{*}{ Ambiente tranquilo } & $\begin{array}{l}\text { Gosto de bistrô pois as pessoas não falam } \\
\text { alto }\end{array}$ & Atividade \\
\hline & & $\begin{array}{l}\text { Iluminação tem que ser intimista. Pouca } \\
\text { luz deixa as pessoas mais calmas }\end{array}$ & Vida \\
\hline & $\begin{array}{l}\text { Ambiente propicio para } \\
\text { uma conversa }\end{array}$ & $\begin{array}{l}\text { Eu gosto de lugar que eu possa ficar } \\
\text { conversando na mesa como eu faço na } \\
\text { minha casa }\end{array}$ & $\begin{array}{c}\text { Atividade/Vid } \\
\text { a }\end{array}$ \\
\hline \multirow[b]{2}{*}{ Segurança } & Aversão a surpresas & Gosto de saber o que está me esperando & Vida \\
\hline & $\begin{array}{l}\text { Presença de um } \\
\text { responsável }\end{array}$ & $\begin{array}{l}\text { O lugar recebe toda minha credibilidade } \\
\text { quando percebo que tem alguém } \\
\text { integralmente responsável pelo bistrô. }\end{array}$ & Vida \\
\hline
\end{tabular}




\begin{tabular}{|c|c|c|c|}
\hline Organização & $\begin{array}{l}\text { Comprometimento com } \\
\text { as reservas }\end{array}$ & $\begin{array}{l}\text { Gosto de chegar no bistrô e ter minha } \\
\text { mesa reservada no horário que eu pedi. }\end{array}$ & Atividade \\
\hline Hospitalidade & $\begin{array}{l}\text { Atendimento } \\
\text { personalizado }\end{array}$ & $\begin{array}{l}\text { Neste tipo de lugar o atendimento é } \\
\text { sempre cortês inclinado a te deixar a } \\
\text { vontade. }\end{array}$ & Atividade \\
\hline \multirow{5}{*}{$\begin{array}{l}\text { Sentir-se } \\
\text { cuidada }\end{array}$} & $\begin{array}{l}\text { Necessidade de ser } \\
\text { notado }\end{array}$ & $\begin{array}{l}\text { Gosto de ir em locais que as pessoas } \\
\text { percebam que eu estou chegando. }\end{array}$ & Vida \\
\hline & Sensação de amparo & Gosto de bistrô com apelo de casa & Vida \\
\hline & Personalização & $\begin{array}{l}\text { Gosto de chegar em um lugar e saber que } \\
\text { farão algo especialmente para mim. }\end{array}$ & Vida \\
\hline & $\begin{array}{l}\text { Cozinhar como um ritual } \\
\text { de doação }\end{array}$ & $\begin{array}{l}\text { Acho que cozinhar é um ato de doação } \\
\text { ao próximo. }\end{array}$ & Vida \\
\hline & $\begin{array}{l}\text { Refeição como uma } \\
\text { pausa no dia. }\end{array}$ & $\begin{array}{l}\text { Comer em bistrô te dá a chance de dar } \\
\text { uma pausa e ter uma refeição tranquila. }\end{array}$ & Atividade \\
\hline Afeto & $\begin{array}{l}\text { Comida como uma } \\
\text { representação de afeto }\end{array}$ & $\begin{array}{l}\text { Minha mãe cozinhou para mim a vida } \\
\text { toda. }\end{array}$ & Vida \\
\hline $\begin{array}{l}\text { Sentir-se } \\
\text { bem/Bem- } \\
\text { estar }\end{array}$ & $\begin{array}{l}\text { Atmosfera que faz sentir } \\
\text { bem }\end{array}$ & $\begin{array}{l}\text { Sentir-se a vontade. É uma sensação boa } \\
\text { estar em um bistrô. }\end{array}$ & Vida \\
\hline \multirow{2}{*}{$\begin{array}{l}\text { Comunicação } \\
\text { externa }\end{array}$} & $\begin{array}{l}\text { Previsibilidade do } \\
\text { modelo de serviço }\end{array}$ & $\begin{array}{l}\text { Gosto de saber todas informações que } \\
\text { preciso: preço, prato do dia, horários... }\end{array}$ & Produto \\
\hline & Controle de expectativas & $\begin{array}{l}\text { Gosto de ter uma pista sobre os locais } \\
\text { que eu vou frequentar. }\end{array}$ & Vida \\
\hline \multirow[b]{2}{*}{$\begin{array}{l}\text { Comunicação } \\
\text { no bistrô }\end{array}$} & \multirow[b]{2}{*}{$\begin{array}{l}\text { Informação ao alcance } \\
\text { do usuário }\end{array}$} & $\begin{array}{l}\text { Não gosto de ir em lugares que a comida } \\
\text { tem nomes complicados. }\end{array}$ & \multirow[b]{2}{*}{ Produto } \\
\hline & & $\begin{array}{l}\text { O fato do bistrô não ter menu não } \\
\text { significa que as informações de preço e } \\
\text { opções de sobremesas não devem estar } \\
\text { acessíveis aos olhos. }\end{array}$ & \\
\hline
\end{tabular}

Fonte: Elaborado pelos autores

Por fim, a condução das entrevistas em profundidade com os usuários se deu de forma a investigar o relacionamento e a interação desta população com os bistrôs, sob a perspectiva das experiências envolvidas. Dentre os principais tópicos abordados nessas entrevistas, foram discutidos aspectos relacionados a identificação; hábitos alimentares; expectativas; características motivadoras de escolha e afastamento; e aspectos de representações do evento em torno da mesa.

\subsection{Análise dos especialistas sobre o potencial do concern profile para o desenvolvimento de projetos de operações gastronômicas}

Após analisar os concerns dos usuários de bistrôs, formando um concern profile, a segunda etapa da pesquisa foi caracterizada pela entrega destas informações aos experts (especialistas que integraram o grupo focal) para que pudessem avaliar a importância da utilização do concern profile para fomentar projetos de bistrôs.

A partir do grupo focal realizado, os especialistas manifestaram que, na sua prática profissional, normalmente não se conectam diretamente com os usuários para começar a pensar em um projeto de operação gastronômica. Ao passo que manifestaram a importância de conhecer os desejos e objetivos do cliente final, não possuem o hábito de contemplarem estas informações no processo de projeto. 0 depoimento que segue representa essa prática: "a gente não pensa se tem pesquisa...basicamente, chega um plano de negócios que diz quantas pessoas preciso 
atender, qual o produto, quanto deve faturar, e a gente tenta estabelecer um layout que favoreça este fluxo (...)".

Os especialistas deixaram claro que há uma separação de momentos projetuais que são conduzidos por profissionais de áreas distintas que, na maioria das vezes, não discutem a sinergia entre as premissas de projeto de uma forma geral, havendo orientações de projeto distintas conforme a especialidade do profissional envolvido. Isso ocorre mesmo tendo como ponto de partida o mesmo plano de negócio que caracteriza em termos genéricos a operação gastronômica a ser desenvolvida.

Os especialistas foram incentivados a discutirem sobre a origem das decisões que depositam nos projetos. Neste viés, manifestaram que, muitas vezes, as decisões de projeto são tomadas de acordo com percepções individuais de cada um dos profissionais. Foi evidenciado que os especialistas acreditam que o designer projeta considerando seu processo individual intuitivo, ou seja, de acordo com as falas dos participantes pode-se perceber que o repertório mental de cada um influencia na tomada de decisões projetuais.

A partir da apresentação e da discussão dos concerns dos usuários, os especialistas foram incubidos em identificar diretrizes projetuais para cada categoria do perfil previamente coletado. 0 quadro que segue apresenta esses resultados a partir do concern profile.

Quadro 2 - 0 concern profile e as ações de projeto

\begin{tabular}{|c|c|c|c|c|c|}
\hline $\begin{array}{l}\text { Categorias } \\
\text { de análise }\end{array}$ & $\begin{array}{l}\text { Afirmativas } \\
\text { de Concerns }\end{array}$ & $\begin{array}{l}\text { Frase que } \\
\text { representa o } \\
\text { concern }\end{array}$ & $\begin{array}{l}\text { Tipolo } \\
\text { gia }\end{array}$ & Ações de projeto & $\begin{array}{l}\text { Dimensões } \\
\text { SPS }\end{array}$ \\
\hline $\begin{array}{l}\text { Qualidade } \\
\text { da comida }\end{array}$ & $\begin{array}{l}\text { Apresentação } \\
\text { do prato }\end{array}$ & $\begin{array}{l}\text { A apresentação } \\
\text { do prato é a } \\
\text { primeira } \\
\text { impressão que se } \\
\text { tem da comida. }\end{array}$ & Produto & $\begin{array}{l}\text { Inclusão de acessórios na } \\
\text { decoração do prato tais } \\
\text { como: louças, flores } \\
\text { comestíveis, ervas frescas, } \\
\text { azeites aromatizados }\end{array}$ & Produto \\
\hline $\begin{array}{l}\text { Ambiente } \\
\text { confortável }\end{array}$ & $\begin{array}{l}\text { Detalhes na } \\
\text { decoração }\end{array}$ & $\begin{array}{l}\text { Gosto de bistrô } \\
\text { cheio de } \\
\text { detalhes pois } \\
\text { eles } \\
\text { complementam } \\
\text { a decoração e } \\
\text { transmitem } \\
\text { conforto. }\end{array}$ & Produto & $\begin{array}{l}\text { Investimento em decoração } \\
\text { e ambientação que priorize } \\
\text { conforto. Iluminação } \\
\text { intimista. Utilização de luz } \\
\text { amarela. Oferta de poucas } \\
\text { mesas. }\end{array}$ & Produto \\
\hline Segurança & $\begin{array}{l}\text { Presença de } \\
\text { um } \\
\text { responsável }\end{array}$ & $\begin{array}{l}\text { O lugar recebe } \\
\text { toda minha } \\
\text { credibilidade } \\
\text { quando percebo } \\
\text { que tem alguém } \\
\text { integralmente } \\
\text { responsável pelo } \\
\text { bistrô. }\end{array}$ & Vida & $\begin{array}{l}\text { Fluxograma de } \\
\text { atendimento. Desenhar as } \\
\text { hipóteses de eventuais } \\
\text { problemas para capacitar } \\
\text { equipe }\end{array}$ & Serviço \\
\hline Organização & $\begin{array}{l}\text { Comprometi } \\
\text { mento com } \\
\text { as reservas }\end{array}$ & $\begin{array}{l}\text { Gosto de chegar } \\
\text { no bistrô e ter } \\
\text { minha mesa } \\
\text { reservada no } \\
\text { horário que eu } \\
\text { pedi. }\end{array}$ & Atividade & $\begin{array}{l}\text { Processualização do } \\
\text { atendimento de reserva }\end{array}$ & Comunicação \\
\hline
\end{tabular}




\begin{tabular}{|c|c|c|c|c|c|}
\hline Hospitalidade & $\begin{array}{l}\text { Atendimento } \\
\text { personalizado }\end{array}$ & $\begin{array}{l}\text { Neste tipo de } \\
\text { lugar o } \\
\text { atendimento é } \\
\text { sempre cortês } \\
\text { inclinado a te } \\
\text { deixar a vontade. }\end{array}$ & Atividade & $\begin{array}{l}\text { Necessidade de avaliar as } \\
\text { três dimensões do SPS para } \\
\text { sugestão de diretrizes }\end{array}$ & $\begin{array}{l}\text { Produto } \\
\text { Serviço } \\
\text { Comunicação }\end{array}$ \\
\hline \multirow[b]{2}{*}{$\begin{array}{l}\text { Sentir-se } \\
\text { cuidada }\end{array}$} & $\begin{array}{l}\text { Sensação de } \\
\text { amparo }\end{array}$ & $\begin{array}{l}\text { Gosto de bistrô } \\
\text { com apelo de } \\
\text { casa }\end{array}$ & Vida & $\begin{array}{l}\text { Escolha do ponto comercial } \\
\text { priorizando que seja uma } \\
\text { casa. Conceito de ter um } \\
\text { jardim com horta e árvore } \\
\text { frutífera. }\end{array}$ & $\begin{array}{l}\text { Produto } \\
\text { Serviço } \\
\text { Comunicação }\end{array}$ \\
\hline & $\begin{array}{l}\text { Refeição } \\
\text { como uma } \\
\text { pausa no dia. }\end{array}$ & $\begin{array}{l}\text { Comer em bistrô } \\
\text { te dá a chance } \\
\text { de dar uma } \\
\text { pausa e ter uma } \\
\text { refeição } \\
\text { tranquila. }\end{array}$ & Atividade & $\begin{array}{l}\text { Proposta de dois horários de } \\
\text { almoço com preço } \\
\text { diferenciado }\end{array}$ & Comunicação \\
\hline Afeto & $\begin{array}{l}\text { Comida como } \\
\text { uma } \\
\text { representação } \\
\text { de afeto }\end{array}$ & $\begin{array}{l}\text { Minha mãe } \\
\text { cozinhou para } \\
\text { mim a vida toda. }\end{array}$ & Vida & $\begin{array}{l}\text { Necessidade de avaliar as } \\
\text { três dimensões do SPS para } \\
\text { sugestão de diretrizes }\end{array}$ & $\begin{array}{l}\text { Produto } \\
\text { Serviço } \\
\text { Comunicação }\end{array}$ \\
\hline $\begin{array}{l}\text { Sentir-se } \\
\text { bem/Bem- } \\
\text { estar }\end{array}$ & $\begin{array}{l}\text { Atmosfera } \\
\text { que faz sentir } \\
\text { bem }\end{array}$ & $\begin{array}{l}\text { Sentir-se à } \\
\text { vontade. É uma } \\
\text { sensação boa } \\
\text { estar em um } \\
\text { bistrô. }\end{array}$ & Vida & $\begin{array}{l}\text { Necessidade de avaliar as } \\
\text { três dimensões do SPS para } \\
\text { sugestão de diretrizes }\end{array}$ & $\begin{array}{l}\text { Produto } \\
\text { Serviço } \\
\text { Comunicação }\end{array}$ \\
\hline $\begin{array}{l}\text { Comunicação } \\
\text { externa }\end{array}$ & $\begin{array}{l}\text { Previsibilidade } \\
\text { do modelo de } \\
\text { serviço }\end{array}$ & $\begin{array}{l}\text { Gosto de saber } \\
\text { todas } \\
\text { informações que } \\
\text { preciso: preço, } \\
\text { prato do dia, } \\
\text { horários... }\end{array}$ & Produto & $\begin{array}{l}\text { Indicação de informações } \\
\text { claras em e-mail e redes } \\
\text { sociais bem como na lousa. } \\
\text { Indicação de precificação } \\
\text { diferenciada. }\end{array}$ & $\begin{array}{l}\text { Produto e } \\
\text { Comunicação }\end{array}$ \\
\hline $\begin{array}{l}\text { Comunicação } \\
\text { no bistrô }\end{array}$ & $\begin{array}{l}\text { Informação } \\
\text { ao alcance do } \\
\text { usuário }\end{array}$ & $\begin{array}{l}\text { Não gosto de ir } \\
\text { em lugares que a } \\
\text { comida tem } \\
\text { nomes } \\
\text { complicados. }\end{array}$ & Produto & $\begin{array}{l}\text { Aplicar a linguagem técnica } \\
\text { quando ela venha a } \\
\text { contribuir com as } \\
\text { motivações de escolha do } \\
\text { usuário }\end{array}$ & Comunicação \\
\hline
\end{tabular}

Fonte: Elaborado pelos autores

A partir dos relatos dos participantes, percebeu-se que a maior contribuição que o concern profile alcançou no grupo focal foi de que a promoção de soluções para atender o mercado de usuários de bistrô fomenta de forma concreta as decisões de projeto quando é trabalhada entre uma equipe multidisciplinar na qual vários pontos de vista enriquecem a tomada de decisão. Além disso, o desdobramento dos elementos que compõem a experiência emocional do usuário (concerns) e sua organização em categorias associadas a decisões de elementos de um projeto (produto, serviço, comunicação), possibilitam o desenvolvimento de diretrizes projetuais mais facilmente identificadas e passíveis de comunicação mais clara entre os participantes de uma equipe de projeto de uma operação gastronômica.

Entretanto, alguns desafios se estabelecem na construção e no uso de concern profile em projetos de desenvolvimentos de operações gastronômicas, como a classificação desses concerns. A pesquisa proporcionou a observação de que os concerns relacionados à vida (objetivos e valores individuais), não diretamente associados a situação de consumo em questão, por serem demandas abstratas, podem 
sugerir várias interpretações, possibilitando a geração de um maior número de ideias. Entretanto, os participantes apresentaram dificuldade de traduzir esta abstração em uma ideia concreta de projeto, como foi o caso da observação ao concern minha mãe cozinhou para mim a vida toda (concerns relacionado à vida). Sugere-se que, quando os elementos do concern profile não são bem definidos, o projetista pode ter dificuldade em propor alternativas. Maiores esforços na decomposição deste concern poderia gerar parâmetros mais objetivos para que estas informações fossem revertidas em suporte para a tomada de decisões projetuais.

Ademais, como a lente teórica utilizada neste estudo foi a Teoria dos Appraisals que propõe uma relação de causalidade entre características pessoais (demandas, conjunto de interesses, padrões) tencionadas com um estímulo, o desmembramento do concern a ser observado é vital. A avaliação que o usuário irá fazer desta relação é que será responsável pelo desencadear de uma emoção positiva ou negativa (DESMET, 2007; DESMET, 2002; TONETTO; COSTA, 2011). Logo, se o concern que o designer estiver observando possibilitar muitas interpretações, possivelmente, será mais difícil traduzir em ideias de projeto ações concretas para atender tal demanda. Neste caso, o projetista pode indicar várias características que o estímulo deverá conter para que o tensionamento com o concern potencialize que a avaliação seja na direção de uma aproximação do usuário com a oferta (maior tempo de permanência, intenção de recompra, recomendação). No caso desse concern discutido acima, o estímulo pode ser a decoração rústica, com tons quentes; pode ser a oferta de um menu com refeições caseiras e nomenclaturas simples; pode ser a figura de uma cozinheira com estereotipo de dona de casa, entre outras indicações.

Por outro lado, os resultados observados acerca dos concerns relacionados a produto e atividade trouxeram outra perspectiva. Os desdobramentos em ações projetuais que foram sugeridos demonstraram que, na maioria das vezes, as demandas que fazem referência a características estéticas, de comunicação, de funcionalidade e elementos técnicos do produto tendem a gerar sugestões mais objetivas. Foi o que ocorreu, por exemplo, com o concern não gosto de ir a lugares em que a comida tem nomes complicados. Neste caso, o concern é relacionado a produto e as sugestões de solução para atendê-lo foram no sentido de minimizar a utilização de linguagem técnica para descrever a comida de bistrô. Quando se está projetando para despertar uma experiência positiva, o desejo do usuário não pode deixar de ser considerado no projeto ainda que, muitas vezes, como neste caso da linguagem aplicada nos menus, a escrita técnica usualmente é utilizada para elevar pratos simples em pratos sofisticados.

De acordo com tudo que foi exposto na discussão acima, é possível sugerir que os concerns relacionados à vida requerem um desdobramento mais objetivo para facilitar e potencializar que soluções sejam propostas. Esta tipologia e a sua vinculação à união dos três elementos do SPS para que o fomento de insights projetuais se realize, encontra respaldo nos estudos de Meroni (2008) e Zurlo (2010). Os autores observam que se tem um sistema produto-serviço (SPS) quando se fala em agir estratégico não limitado a um processo exclusivo de serviço ou comunicação ou produto. A força que um SPS possui está justamente na união dos três elementos e na força relacionada que um elemento proporciona ao outro quando articulados. 


\section{CONCLUSÕES}

O estudo ora apresentado permitiu analisar a contribuição que o uso de um tipo de informação sobre a experiência do usuário (perfil de concerns) pode contribuir para o desenvolvimento de sistemas produto-serviço em um contexto especifico. Dos elementos que constituem o concern profile é possível construir indicações de projeto que se aproximam de soluções para estas demandas. Logo, quando se trata de projetar com o objetivo específico de potencializar emoções positivas nos usuários, é imprescindível que informações sobre seus desejos sejam analisadas e inseridas nas decisões de projeto. Adotar uma postura diferente pode induzir o projetista a propor soluções intuitivas, ou seja, a induzir que a tomada de decisões projetuais seja influenciada pelo repertório mental individual ao invés de considerar informações detalhadas sobre os desejos dos usuários, elevando o risco de sucesso do sistema produto-serviço desenvolvido.

É importante ressaltar que os especialistas analisados avaliaram como muito importante a utilização de um concern profile para fomentar um projeto de bistrô considerando o viés do design estratégico, pois permite que as informações contribuam para um pleno entendimento sobre as motivações e interesses do potencial cliente. Ao mesmo tempo em que, algumas vezes, tenham trabalhado as dimensões do SPS de forma separada, sugere-se que, para potencializar a oferta de uma experiência positiva, ou seja, para sugerir diretrizes de projeto que potencializem reações positivas nos usuários, trabalhar o SPS de forma integrada maximiza a possibilidade deste resultado. Esta indicação está embasada também na orientação de autores (MERONI, 2008; ZURLO, 2010) os quais explicam que o SPS possui como premissa a entrega de soluções que são apresentadas como um sistema, no qual o produto, o serviço e a comunicação interagem e não devem ser observadas de forma isolada.

Para tratar o concern profile como insumo projetual para a promoção de diretrizes, é importante deixar claro que, nesta pesquisa, optou-se por avaliar esta possibilidade em uma equipe multidisciplinar de trabalho. Retomando alguns conceitos da fundamentação teórica, a multidisciplinaridade é uma característica importante do design estratégico (ZURLO, 2010). Através de diversos pontos de vista de diferentes disciplinas é possível alcançar o entendimento das novas maneiras de consumir que pode visar além da forma e função, outras necessidades e desejos dos consumidores. O design estratégico é caracterizado como uma abordagem projetual com característica de processo aberto, com interpretações e conhecimentos disciplinares articulados. Opera em âmbitos coletivos e finaliza a operacionalidade em um SPS. Em outras palavras, um SPS é um mix de produto, serviço e comunicação que gera um efeito de sentido resultando não apenas em soluções pontuais, mas em um sistema de oferta (ZURLO, 2010).

Recorrem-se aqui as características conceituais do designer estratégico: a articulação entre produto, serviço e comunicação é um atributo do pensamento sistêmico deste profissional. Capacidade de ver, prever e fazer ver possibilitam todas as condições para que produto, serviço e comunicação sejam relacionados entre si e confrontados com as mudanças nos hábitos comportamentais de consumo. $O$ designer estratégico pode atuar como o mediador desta conversa e produzir a organização das idéias e das tomadas de decisões. 


\section{REFERÊNCIAS}

DEMIR, E.; OZKARAMANLI, D.; DESMET, P. M. A. How to design for emotions: experiences in a course. In: PROCEEDINGS OF THE INTERNATIONAL DESIGN \& EMOTION CONFERENCE, 7., 2010. Chicago. Anais... Chicago, 2010. Material em PDF. DEMIR, E; DESMET, P; HEKKERT, P. Appraisal patterns of emotions in human-product interaction. International Journal of Design, [S.I.], v.3, n. 2, p. 41-51, 2009. Material em PDF.

DESMET, P. M. A. Designing emotions. Delft University of Technology, 2002. Material em PDF: Tese de Doutorado não publicado

DÓRIA, Carlos. A culinária materialista. São Paulo: SENAC, 2009.

FONTANELLA, B.; RICAS, J; TURATO, E. Amostragem por saturação em pesquisas qualitativas em saúde: contribuições teóricas. Cadernos de Saúde Pública, São Paulo, v. 24, n. 1, p. 17-27, 2008. Material em PDF.

MERONI, A. Strategic design: where are we now? Reflection around foundantions of a recent discipline. Strategic Design Research Journal, [S.I.], v. 1, n. 1, p. 31-38, 2008. Material em PDF.

MORAES, R. Análise de conteúdo. Revista Educação, [S.I.], v. 22, n. 37, p. 7-32, 1999. Material em PDF.

OZKARAMANLI, D.; DESMET, PMA. I knew I shouldn't, yet I did it again! Emotion-driven design as a means to subjective well-being. International Journal of Design, [S.I.], v. 6, n. 1, p. 27-39, 2012. Material em PDF.

REYNOLDS \& GUTMAN. Laddering theory, method, analysis and interpretation. Journal of Advertising Research, January-February, 1988

TONETTO, L. A perspectiva cognitiva no design para emoção: análise de concerns em projetos para a experiência. Strategic Design Research Journal, [S.I.], v. 5, n. 3, p. 99106, 2012. Material em PDF.

TONETTO, L.; COSTA, F. Design emocional: conceitos, abordagens e perspectivas de pesquisa. Strategic Design Research Journal, [S.I.], v. 4, n. 3, p. 132-140, 2011. Material em PDF.

ZURLO, F. Design strategico. In: AA. VV. Gli spazi e le arti. Roma: Enciclopedia Treccani, 2010. v. 4: Opera XXI Secolo. 